\title{
Secondary bacterial infections in patients with COVID-19
}

\author{
Alexandra Lachana ${ }^{1}$, Evangelia Chrysanthopoulou ${ }^{1}$, Fotini Vakiarou ${ }^{1}$, George Dimopoulos ${ }^{1}$
}

\begin{abstract}
Coronavirus Disease 2019 (COVID-19) has been classified as a global threat, affecting millions of people and killing thousands. It is caused by the SARSCoV-2 virus, which emerged at the end of 2019 in Wuhan, China, quickly spreading worldwide. Patients' clinical features vary, and secondary infections represent a constant risk of increased mortality among those who need hospitalization. Damaged respiratory epithelium and dysregulation of the immune response are the main pathophysiological mechanisms of increased microbial adhesion to the airway epithelial cells and the development of secondary infections. However, the exact incidence of secondary infections in COVID-19 patients is not thoroughly known (3.2\%-80\%) due to limited and heterogeneous studies that lead to conflicting or non-comparable results. Infection-risk stratification in critically ill patients includes early ICU admission (within 48 hours from hospitalization), age, comorbidity, immunosuppressive drugs administration, and disease severity indexes (oxygenation, inflammation, and cytolysis score). In treating secondary infections, the local epidemiology (which usually includes multidrug-resistant strains) and the modification of any antibiotic regimen according to the cultures' results are critical. Prompt and appropriate antimicrobial agents represent the cornerstone in secondary infection treatment for COVID-19 hospitalized patients.
\end{abstract}

\author{
AFFILIATION \\ 1 Department of Critical Care, Attikon \\ University General Hospital, School of \\ Medicine, National and Kapodistrian \\ University of Athens, Athens, Greece
}

\section{CORRESPONDENCE TO}

Alexandra Lachana. Department of Critical Care, National and Kapodistrian University of Athens, School of Medicine, Attikon University General Hospital, 1 Rimini Street, Athens, 12462, Greece. E-mail: alekalahana2013@gmail.com

\section{KEYWORDS}

COVID-19, severely ill, secondary infections

Received: 28 January 2021

Revised: 31 January 2021

Accepted: 3 February 2021

\section{INTRODUCTION}

During the period December 2019-December 2020, the SARS-CoV-2 has infected more than 70 million people and caused far more than 1.6 million deaths worldwide ${ }^{1}$. SARSCoV-2 contains monoclonal RNA, has a spherical structure with characteristic corona-like glycoprotein projections, hence the name Corona Virus (CoV), and causes the disease COVID-19 (Corona Virus Disease-19) ${ }^{2-4}$. SARS-CoV-1, another coronavirus, was responsible for the outbreak of Severe Acute Respiratory Syndrome (SARS) in 2003 and the Middle East Respiratory Syndrome (MERS) in $2007^{5}$. Although mostly asymptomatic, COVID-19 sometimes presents with mild symptoms, myalgias, taste and smell changes in some cases, or moderate pneumonia. Less commonly, COVID-19 manifests as severe pneumonia and Acute Respiratory Distress Syndrome (ARDS), mainly affecting older patients and people with previous comorbidities and inducing high mortality ${ }^{6}$. Specific treatment for COVID-19 is currently not available, and its management mainly consists of preventing transmission by avoiding exposure to the virus. The WHO (World Health Organization) recommends adopting hygiene measures, such as frequent and thorough handwashing with soap and water, antiseptics use, smoking cessation, social distancing, and application of face-nose masks ${ }^{7}$. The recommended treatment for non-critically ill patients includes oxygen, dexamethasone, and remdesivir administration. Dexamethasone appears to increase patients' survival requiring oxygen therapy or invasive mechanical ventilation, while remdesivir may reduce their hospital stay $^{8,9}$. Newer antiviral drugs and monoclonal antibodies are under evaluation. In ICU patients with COVID-19 additional hemodynamic and organ support is often necessary ${ }^{5}$. In intubated and non-intubated patients, the prone position appears useful, while extracorporeal oxygenation (ECMO) benefits selected patients. During their hospitalization, patients with COVID-19 develop secondary bacterial infections. The present article attempts to provide a comprehensive review of the currently available literature on secondary bacterial infections in COVID-19 patients.

\section{REVIEW}

Secondary infections in patients with COVID-19

Data on the frequency and characteristics of secondary infections in patients with COVID-19 are limited and conflicting. Initially, studies in China, the United States, and the United Kingdom identified bacterial infections in this group of patients as minor ${ }^{10-13}$. A retrospective study from the UK included 836 patients with confirmed SARS-CoV-2 infection and a control group of flu patients of the same period (2019-2020). In the first five days of hospitalization of patients with COVID-19, the rate of bacterial infections was $3.2 \%$. This percentage amounted to $6.1 \%$ throughout their hospitalization, without reported fungal infections. The results were similar to those of the control group ${ }^{14}$. 
Another retrospective study of 918 patients with COVID-19 from Wuhan, China, found that only $7.1 \%$ developed a fungal or bacterial infection, such as pneumonia (32.3\%), bacteremia (24.6\%), and urinary tract infection (21.5\%) ${ }^{15}$. Also, in 150 hospitalized patients with COVID-19 in Wuhan, China, the secondary bacterial infection incidence was 15\%; however, among non-survivors, this rate rose to $50 \%{ }^{16}$. In another study of 41 patients with COVID-19 from Wuhan, only four patients (10\%) developed a secondary infection. However, only thirteen patients (32\%) entered the ICU, of which six (15\%) died ${ }^{17}$. In another study, the most common complications in 113 non-survivors with COVID-19 were sepsis due to Acinetobacter baumannii or Klebsiella pneumoniae and $\mathrm{ARDS}^{10}$. Respiratory tract infections were reported in 24 of 30 patients with COVID-19 (80\%) in Qingdao, China, who developed IgM antibodies to influenza A virus (60\%) and influenza B virus (53\%), Mycoplasma pneumoniae (23.3\%), and Legionella pneumophila (20\%). Strikingly, the incidence of identical infections in patients with community-acquired pneumonia from the same geographical area was only $20.90 \%{ }^{18}$. Also, elderly patients (>60 years) with COVID-19 often develop bacterial infections $(42.8 \%)^{19}$. The rate of bloodstream infections in ICU reaches approximately $25 \%$ after the 15 th day of hospitalization and $50 \%$ after the 30 th day ${ }^{20}$. The incidence of COVID-19-associated pulmonary aspergillosis (COVIDAssociated Pulmonary Aspergillosis - CAPA) varies from $4 \%$ to $35 \%$, depending on the type of study (retrospective or prospective) $)^{21}$. Eventually, according to a recent metaanalysis, the prevalence of confirmed bacterial infections in ICU admitted patients with COVID-19 is approximately 14\%, without being classified as early or late la $^{22}$.

\section{Pathophysiology of secondary infections in patients with COVID-19}

Damage to the respiratory epithelium

The first line of defence of the respiratory system is the mucosal 'device' (cilia). The mucus covering the airway epithelium contains mainly glycoproteins (mucins) that support innate immunity through their antiviral and antiinflammatory properties and allow viruses to be trapped and cleared $^{23-25}$. After the virus invades the airways, epithelial cells produce the classical interferons (INFs), especially INF-a and INF-b, limiting virus spread ${ }^{26-28}$. In the airways' epithelium, microorganisms' recognition by special receptors occurs, triggering immune reactions by detecting bacterial and viral components. Infection of the airway epithelium by viruses leads to increased expression of platelet-activating factor receptors (PDF-r) and intracellular adhesion molecule-1 (ICAM-1), causing the chemotaxis of macrophages, neutrophils, natural killer cells, and eosinophils from the bloodstream to the site of infection ${ }^{29}$.

Dysregulation of the immune response

Viral infections interfere with mucosal clearance, resulting in increased adhesion of bacteria to the mucosa and bacterial colonies' formation. Excessive mucus concentration (as a reaction to viral infection) also inhibits the accumulation of immune cells and antibacterial molecules ${ }^{30}$. Besides, cell death impairs pathogenic microbes' mechanical clearance and promotes the emergence of new receptors for bacterial adhesion or leads to biofilm formation, mainly by Str. pneumoniae ${ }^{31,32}$. Increased bacterial adhesion, caused by increased surface receptor expression (e.g. by PAF-r involved in the penetration of Str. pneumoniae into the respiratory epithelium) and by desensitized Toll-Like Receptors (TLRs) of lung cells (due to the action of viruses), contributes to the development of secondary bacterial infection ${ }^{33}$. The TLR4 and TLR5 channels change in shape, resulting in decreased neutrophil chemotaxis and increased bacterial adhesion, such as Str. pneumoniae and Pseudomonas aeruginosa, in the airway epithelial cells ${ }^{34,35}$. Other bacteria such as S. aureus are incorporated into the respiratory epithelial cells and cause a further increased ICAM-1 expression ${ }^{36}$.

On the other hand, activation of TLRs induces the synthesis of INFs, which enhance the inflammatory response. The interaction of viruses and host cells leads to the secretion of inflammatory cytokines (e.g. TNF-a), which despite their bactericidal activity, can be harmful, causing the appearance of a hyperinflammatory reaction (cytokine storm), characterized by increased mortality ${ }^{26,35,37}$. The risk of secondary infections is higher in patients with hypoxemic respiratory failure (with or without severe lymphopenia) who need ICU admission in the early stages of the disease $(<48$ hours) (Table 1). Advancing age, comorbidities, concomitant administration of immunosuppressive agents, or increased inflammatory markers ( $C$ reactive protein and ferritin) are not substantial risk factors for secondary infections ${ }^{38}$.

\section{Treatment of secondary infections in patients with COVID-19}

Patients with COVID-19 develop co-infections (bacterial infections that develop simultaneously with the viral infection) and superinfections (bacterial infections that develop during hospitalization). These infections overlap with COVID-19 disease in clinical and laboratory findings and imaging, requiring increased surveillance for their early diagnosis, frequent cultures, and measurement of biomarker levels (e.g. procalcitonin) ${ }^{19,39}$. Table 2 shows the algorithm proposed for the diagnostic approach of these infections.

About $15 \%$ of patients with influenza manifest bacterial co-infections, with the most identified bacteria being Str. pneumoniae, Staph. aureus and Haemophilus influenzae. Patients with COVID-19 are less likely to develop community-associated infections (approximately 8.4\%), and the responsible bacteria's incidence is unknown. In patients with COVID-19 and co-infection, the treatment protocols of community-associated infections are applied, emphasizing Str. pneumoniae infections with the administration of a $\beta$-lactam in combination with a macrolide. In Greece, the 
Table 1. Risk factors for secondary bacterial infections in patients with COVID-19 admitted in ICU

1. Hospitalization time before admission to ICU $<48$ hours

2. COVID-19 disease severity, number of lymphocytes $\left(<0.7 \times 10^{9} / \mathrm{L}\right)$

3. Severity of respiratory failure $\left(\mathrm{PaO}_{2} / \mathrm{FiO}_{2}\right)$

resistance rate of Str. pneumoniae to penicillin is low (about $5.6 \%$ ); however, macrolide is highly resistant (about 4045\%).

Inpatients with COVID-19 experience infections caused by nosocomial pathogens (Klebsiella pneumoniae, Pseudomonas aeruginosa, bacteria that produce broad- spectrum $\beta$-lactamases, Acinetobacter spp, E. coli, Enterococcus spp). Simultaneously, small studies from China reported polymicrobial infections caused by Candida albicans, Acinetobacter baumannii, Klebsiella pneumonia, and Aspergillus fumigatus ${ }^{17,15,40,41}$. The onset of secondary infections depends on patients' comorbidities, use of invasive techniques (e.g. central venous lines placement, hemodialysis techniques) leading to injury of the anatomical defensive barriers (e.g. skin), colonization of the patients, compliance with hand hygiene measures and nurse/patient ratio.

In patients with COVID-19, antimicrobial therapy can be empirical or targeted. The choice of empirical treatment should consider the local epidemiology and antimicrobial resistance profile. The early choice of an appropriate (right drug) and adequate (right dose) antibiotic treatment assumes the knowledge of the local epidemiology (data from the

Table 2. Proposed algorithm for diagnostic approach to secondary bacterial infections in patients with COVID-19 admitted in ICU

\section{Patient with COVID-19}

\section{Upon admission to the ICU \\ Surveillance cultures}

Bronchial secretions, urine sample and rectum specimens $\rightarrow$ to know the flora with which the patient is colonized $\rightarrow$ appropriate empirical antimicrobial treatment awaiting cultures results or when the patient manifests signs of infection and the cultures are negative.

\section{After admitted to the ICU}

Signs and symptoms of infection (fever, leukocytosis, increased CRP and procalcitonin, worsening of CXR and respiratory function, hemodynamic instability needing fluids or vasoconstrictors, unexplained renal failure likely to indicate 'silent sepsis', increased lactic acid levels and unexplained metabolic acidosis ).

\section{Blood cultures}

At least 1 pair of aerobics and anaerobic culture high fever $\rightarrow$ at least 2 pairs of cultures (endocarditis ?) positive cultures $\rightarrow$ RDT (BCID2 or T2MR) to quickly identify the pathogen (within 3 hours). Blood cultures require up to 2 days

\section{Bronchoscopy and BAL}

Cultures for common bacteria as well as fungi (the incidence of CAPA ranging from $4-35 \%)$

Levels of galactomannan (increased in CAPA)

\section{Computed Tomography}

Chest (respirator-related pneumonia or differential diagnosis of non-infectious causes of fever)

Abdominal (ischemic damage due to hypercoagulability associated COVID-19)

Brain (infarct by direct infection of the CNS by the virus or other lesions)

\section{Fever persists and cultures are negative}

1. TEE (endocarditis, vegetations)

2. Lower extremity ultrasound (septic thrombophlebitis)

3. Levels of $1,3-2-D$-glucan (> $80 \mathrm{pg} / \mathrm{mL} \rightarrow$ Candida spp infection $\rightarrow$ pre-emptive antifungal therapy

4. Ophthalmological examination (fungal endophthalmitis)

5. Lumbar puncture (CNS infection, rare in these patients)

6. Continuous obtaining of cultures

7. Check for HIV infection

8. Other infections (TBC, CMV, etc.)

9. Continuous measurement of ferritin levels $\rightarrow$ early diagnosis of hyper-inflammatory syndrome with cytokine storm ( $\uparrow \mathrm{IL}-\mathrm{lb}$ and IL-6) levels

10. Direct insult of CNS

BAL: bronchoalveolar lavage. BCID2: blood cultured identification technique. CAPA: COVID associated pulmonary aspergillosis. CNS: central nervous system. RDT: rapid diagnostic technique. TEE: transesophageal echocardiography. T2MR: T2 magnetic resonance. 
records of the Hospital Infection Committees) and PK/PDs of the selected antibiotics ${ }^{10,15,42,43}$. Subsequently, the physician can de-escalate or escalate the treatment according to the cultures' results and the antibiotics' susceptibility tests ${ }^{42,43}$. Targeted treatment choice should consider the cultures' results (bacterial species), the susceptibility tests, and Minimum Inhibitory Concentration (MIC) of each antibiotic. Procalcitonin levels distinguish between bacterial and viral infection and serve to discontinue or continue antibiotic treatment ${ }^{41,43,44}$.

Often, the local epidemiology differs not only from country to country but also among the same geographical area's hospitals. For this reason, the treatment of secondary infections in patients with COVID-19 cannot follow specific treatment protocols. In China, cephalosporins, carbapenems, and quinolones have been the first-line antibiotics for the treatment of infections, along with the administration of antiviral agents ${ }^{41}$. However, in Greece, the treatment must be different because of the increased incidence of Multi-Drug Resistant (MDR) strains, emphasizing the National Treatment Guidelines for these infections. Besides, the adequate dose of an antibiotic (adequate treatment) depends on specific characteristics of the treated patient (e.g. increased body mass index, increased volume of distribution in septic shock due to capillary leakage, hypoalbuminemia, and renal dysfunction, leading

Figure 1. Main pharmacodynamic parameters of antibiotics. AUC (Area Under the Curve) = area enclosed between Cmax and MIC, indicating the concentration of antibiotic at the site of infection. Cmax (Concentration maximum) $=$ maximum concentration achieved after a dose of antibiotic, MIC (Minimum Inhibitory Concentration) = minimum inhibitory concentration required to fight a bacterium, $t$ (time) $=$ the time at which an antibiotic displays concentrations above MIC

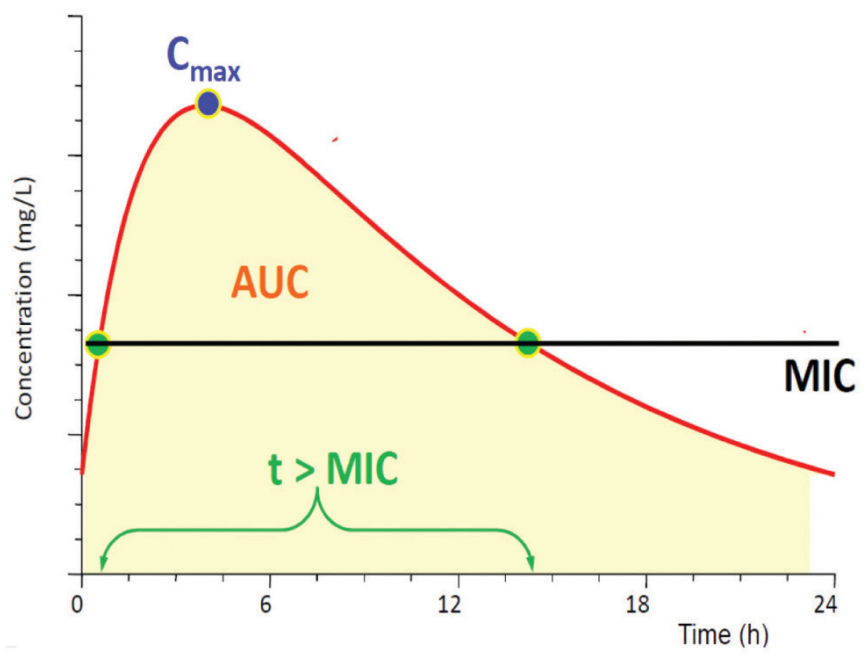

to low concentrations of antibiotics at the site of infection), and the profile of antimicrobial resistance. The optimal dose of an antibiotic also depends on its pharmacokinetic/ pharmacodynamic properties (PK/PDs) (antibiotic dose- or time-dependence, the volume of distribution, augmented creatinine clearance) (Figure 1), targeting in therapeutic concentration at the infection's site without concomitant toxicity. Therapeutic Drugs Monitoring (TDM) is the method to achieve therapeutic concentrations of an antibiotic by measuring its trough levels (minimum concentration before the next dose). The continuous infusion (within 24 hours) of the total daily dose of an antibiotic (mainly $\beta$-lactams) helps to steadily obtain adequate levels of antibiotic concentration (above MIC) at the site of infection (Figure 2$)^{45}$.

Figure 2. Intermittent, prolonged and continuous administration of antibiotics. (A) Intermittent administration of antibiotics. In susceptible pathogens (foi. MIC $0.25 \mathrm{mg} / \mathrm{L}$ ), the concentration of antibiotic at the site of infection ( $A \cup C_{1}$ ), and the time of concentration above MIC [fT $\left.>\mathrm{MIC}_{(0.25 \mathrm{mg} / \mathrm{L})}\right]$ are adequate. When the same pathogen is resistant (f.i. MIC $8 \mathrm{mg} / \mathrm{L}$ ), the same parameters $\left[\mathrm{AUC}_{2}, \mathrm{fT}>\mathrm{MIC}_{(8 \mathrm{mg} / \mathrm{L})}\right]$ are reduced. (B) Prolonged (blue line) and continuous (red line) administration of antibiotics. $\mathrm{AUC}_{3}$ and $\mathrm{fT}>$ $\mathrm{MIC}_{(8 \mathrm{mg} / \mathrm{L})}$ are increased in relation to intermittent administration. Continuous administration shows continuously increased values of the same parameters $^{45}$

a

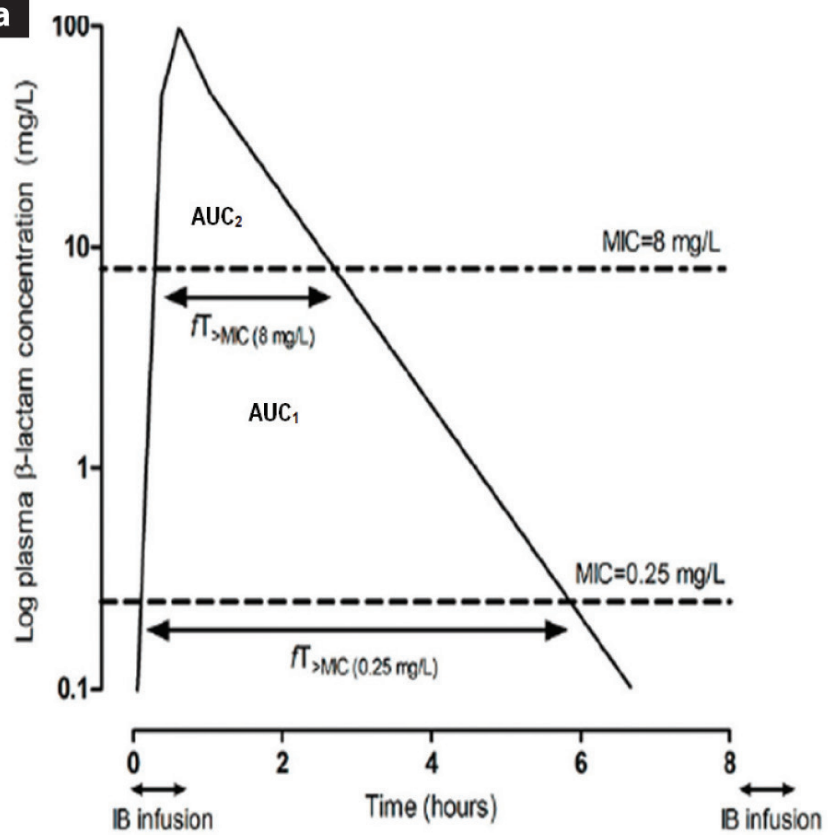


Figure 2. Continued

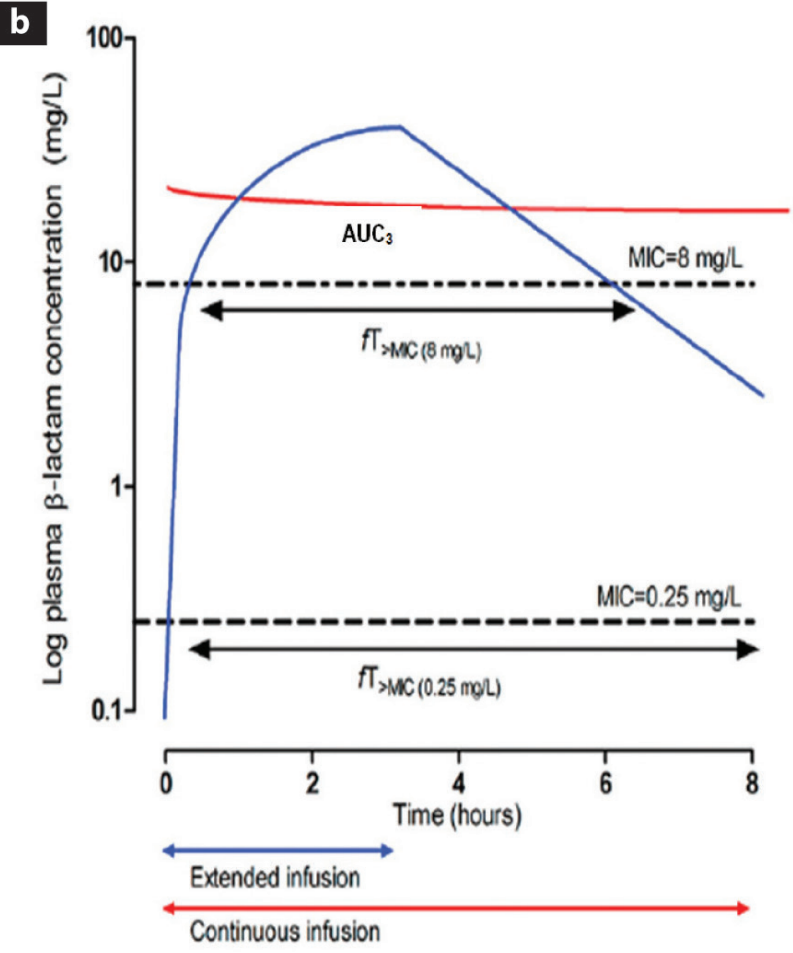

\section{CONCLUSION}

Data on the incidence and characteristics of secondary infections in patients with COVID-19 are currently limited. The risk of bacterial infections increases in patients with COVID-19 admitted to the ICU. The innate immunity of patients with SARS-CoV-2 is impaired, leading to the development of secondary bacterial infections. According to local epidemiology and the antimicrobial resistance pattern, a key issue is choosing an appropriate empirical treatment with broad-spectrum antibiotics. The early, appropriate, and adequate treatment reduces mortality, while of great importance is the de-escalation according to cultures' results and isolated pathogens' susceptibility.

\section{CONFLICTS OF INTEREST}

The authors have completed and submitted the ICMJE Form for Disclosure of Potential Conflicts of Interest and none was reported.

\section{FUNDING}

There was no source of funding for this research.

\section{ETHICAL APPROVAL AND INFORMED CONSENT}

Ethics approval and informed consent were not required for this study.

\section{PROVENANCE AND PEER REVIEW}

Not commissioned; externally peer reviewed.

\section{ПЕРІАНЧН}

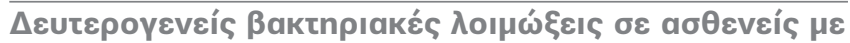
COVID-19

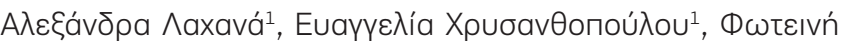

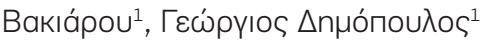

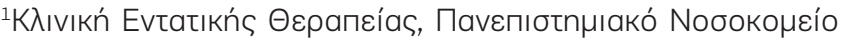
ATTIKON

H vóбos anó tov ıó SARS-CoV-2 (Coronavirus Disease 2019

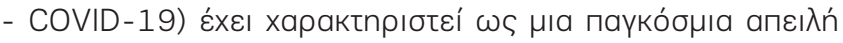

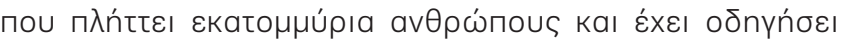

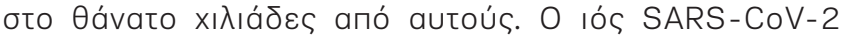

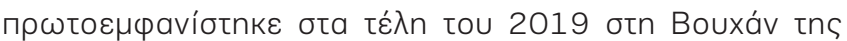

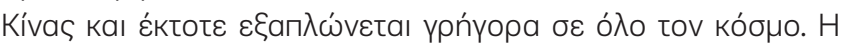

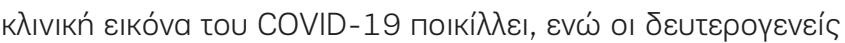

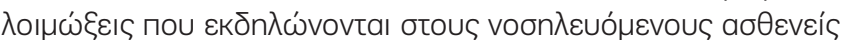

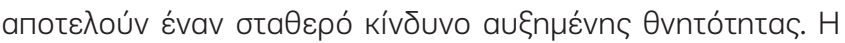

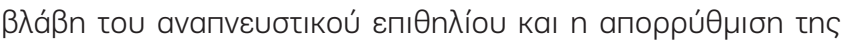

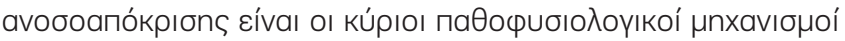

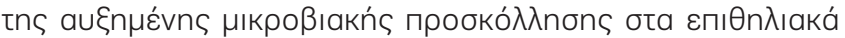

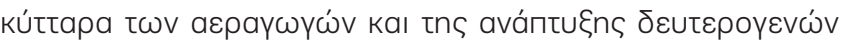

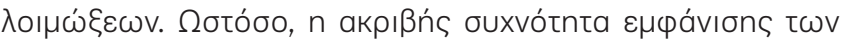

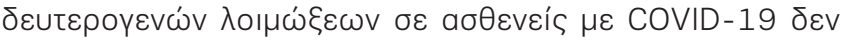

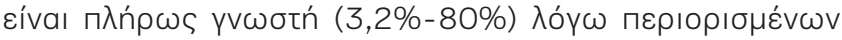

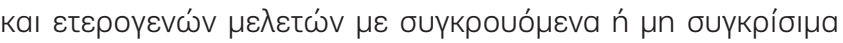

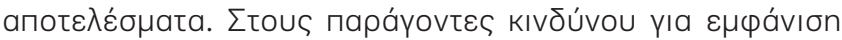

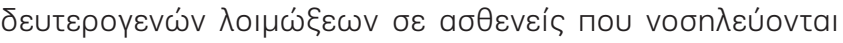

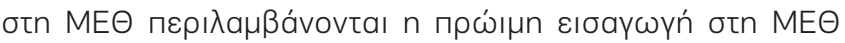

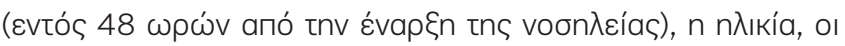

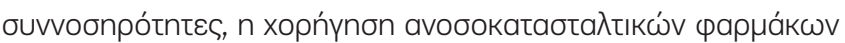

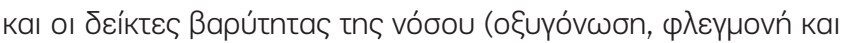

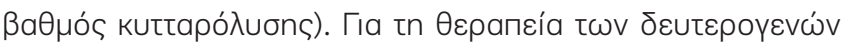

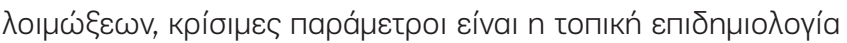

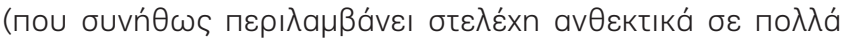

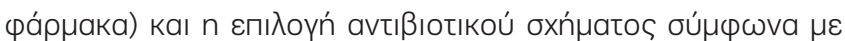

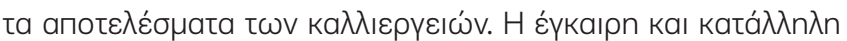

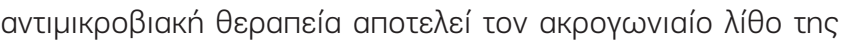

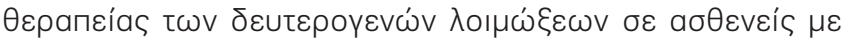

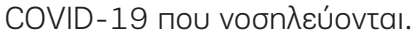

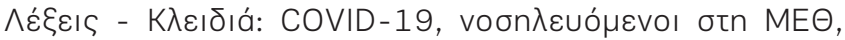

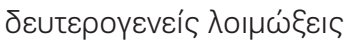

\section{REFERENCES}

1. World Health Organization. COVID-19 Weekly Epidemiological Update. December 1, 2020. Accessed January 31, 2021. https://www.who.int/publications/m/item/weeklyepidemiological-update---1-december-2020

2. Tyrell DA, Bynoe ML. Cultivation of viruses from a high proportion of patients with colds. Lancet. 1966;287(7428):7677. doi:10.1016/S0140-6736(66)92364-6

3. Velavan TP, Meyer CG. The COVID-19 epidemic. Trop Med Int Health. 2020;25(3):278-280. doi:10.1111/tmi.13383

4. Hendaus MA, Jomha FA. Covid-19 induced superimposed bacterial infection. J Biomol Struct Dyn. 2020;1-7. doi:10.1080/07391102.2020.1772110

5. Sahu KK, Mishra AK, Lal A. COVID-2019: update on 
epidemiology, disease spread and management. Monaldi Arch Chest Dis. 2020;90(1):1292. doi:10.4081/monaldi.2020.1292

6. Chavez S, Long B, Koyfman A, Liang SY. Coronavirus Disease (COVID-19): A primer for emergency physicians. Am J Emerg Med. 2020. doi:10.1016/j.ajem.2020.03.036

7. World Health Organization. Coronavirus disease (COVID-19) advice for the public. Updated April 9, 2021. Accessed January 31, 2021. https://www.who.int/emergencies/ diseases/novel-coronavirus-2019/advice-for-public

8. RECOVERY Collaborative Group, Horby P, Lim WS, et al. Dexamethasone in Hospitalized Patients with Covid-19. N Engl J Med. 2021;384(8):693-704. doi:10.1056/NEJMoa2021436

9. Beigel JH, Tomashek KM, Dodd LE, et al. Remdesivir for the Treatment of Covid-19 - Final Report. N Engl J Med. 2020;383(19):1813-1826. doi:10.1056/NEJMoa2007764

10. Chen T, Wu D, Chen $\mathrm{H}$, et al. Clinical characteristics of 113 deceased patients with coronavirus disease 2019: retrospective study. BMJ. 2020;368:m1091. doi:10.1136/bmj.m1091

11. Wu C, Chen X, Cai Y, et al. Risk Factors Associated With Acute Respiratory Distress Syndrome and Death in Patients With Coronavirus Disease 2019 Pneumonia in Wuhan, China. JAMA Intern Med. 2020;180(7):934-943. doi:10.1001/jamainternmed.2020.0994

12. Arentz M, Yim E, Klaff L, et al. Characteristics and Outcomes of 21 Critically III Patients With COVID-19 in Washington State. JAMA. 2020;323(16):1612-1614. doi:10.1001/jama.2020.4326

13. Bhatraju PK, Ghassemieh BJ, Nichols M, et al. Covid-19 in Critically III Patients in the Seattle Region - Case Series. N Engl J Med. 2020;382(21):2012-2022. doi:10.1056/NEJMoa2004500

14. Hughes S, Troise O, Donaldson H, Mughal N, Moore LSP. Bacterial and fungal coinfection among hospitalized patients with COVID-19: a retrospective cohort study in a UK secondary-care setting. Clin Microbiol Infect. 2020;26(10):1395-1399. doi:10.1016/j.cmi.2020.06.025

15. He Y, Li W, Wang Z, Chen H, Tian L, Liu D. Nosocomial infection among patients with COVID-19: A retrospective data analysis of 918 cases from a single center in Wuhan, China. Infect Control Hosp Epidemiol. 2020;41(8):982-983. doi:10.1017/ice.2020.126

16. Ruan Q, Yang K, Wang W, Jiang L, Song J. Clinical predictors of mortality due to COVID-19 based on an analysis of data of 150 patients from Wuhan, China. Intensive Care Med. 2020;46(5):846-848. doi:10.1007/s00134-020-05991-x

17. Huang C, Wang Y, Li X, et al. Clinical features of patients infected with 2019 novel coronavirus in Wuhan, China. Lancet. 2020;395(10223):497-506. doi:10.1016/SO140-6736(20)30183-5

18. Xing Q-s, Li G-j, Xing Y-h. Precautions are Needed for COVID-19 Patients with Coinfection of Common Respiratory Pathogens. MedRxiv. Preprint posted online March 5, 2020. doi:10.1101/2020.02.29.20027698
19. Wang L, He W, Yu X, et al. Coronavirus disease 2019 in elderly patients: Characteristics and prognostic factors based on 4-week follow-up. J Infect. 2020;80(6):639-645. doi:10.1016/j.jinf.2020.03.019

20. Giacobbe DR, Battaglini D, Ball L, et al. Bloodstream infections in critically ill patients with COVID-19. Eur J Clin Invest. 2020;50(10):e13319. doi:10.1111/eci.13319

21. Almiroudi MP, Dimopoulos G. COVID-19 associated Aspergillosis. Pneumon. 2020;33(2):1-4. Accessed January 31, 2021. http://www.pneumon.org/assets/files/789/ file781_688.pdf

22. Lansbury L, Lim B, Baskaran V, Lim WS. Co-infections in people with COVID-19: a systematic review and meta-analysis. J Infect. 2020;81(2):266-275. doi:10.1016/j.jinf.2020.05.046

23. Hendaus MA, Jomha FA, Alhammadi AH. Virus-induced secondary bacterial infection: a concise review. Ther Clin Risk Manag. 2015;11:1265-1271. doi:10.2147/TCRM.S87789

24. Rose MC, Voynow JA. Respiratory tract mucin genes and mucin glycoproteins in health and disease. Physiol Rev. 2006;86(1):245-278. doi:10.1152/physrev.00010.2005

25. Voynow JA, Gendler SJ, Rose MC. Regulation of mucin genes in chronic inflammatory airway diseases. Am J Respir Cell Mol Biol. 2006;34(6):661-665. doi:10.1165/rcmb.2006-0035SF

26. Akira S, Uematsu S, Takeuchi O. Pathogen recognition and innate immunity. Cell. 2006;124(4):783-801. doi:10.1016/j.cell.2006.02.015

27. Basler CF, García-Sastre A. Viruses and the type I interferon antiviral system: induction and evasion. Int Rev Immunol. 2002;21(4-5):305-337. doi:10.1080/08830180213277

28. Katze MG, He Y, Gale M Jr. Viruses and interferon: a fight for supremacy. Nat Rev Immunol. 2002;2(9):675-687. doi:10.1038/nri888

29. Message SD, Johnston SL. Host defense function of the airway epithelium in health and disease: clinical background. J Leukoc Biol. 2004;75(1):5-17. doi:10.1189/jlb.0703315

30. Wilson R, Dowling RB, Jackson AD. The biology of bacterial colonization and invasion of the respiratory mucosa. Eur Respir J. 1996;9(7):1523-1530. doi:10.1183/09031936.96.09071523

31. Bragonzi A, Copreni E, de Bentzmann S, Ulrich M, Conese M. Airway epithelial cell-pathogen interactions. J Cyst Fibros. 2004;3(Suppl 2):197-201. doi:10.1016/j.jcf.2004.05.041

32. Morris DP. Bacterial biofilm in upper respiratory tract infections. Curr Infect Dis Rep. 2007;9(3):186-192. doi:10.1007/s11908-007-0030-3

33. McCullers JA, Rehg JE. Lethal synergism between influenza virus and Streptococcus pneumoniae: characterization of a mouse model and the role of platelet-activating factor receptor. J Infect Dis. 2002;186(3):341-350. doi:10.1086/341462

34. Didierlaurent A, Goulding J, Patel S, et al. Sustained desensitization to bacterial Toll-like receptor ligands after resolution of respiratory influenza infection. J Exp Med. 2008;205(2):323-329. doi:10.1084/jem.20070891 
35. Cook DN, Pisetsky DS, Schwartz DA. Toll-like receptors in the pathogenesis of human disease. Nat Immunol. 2004;5(10):975-979. doi:10.1038/ni1116

36. Passariello C, Schippa S, Conti C, et al. Rhinoviruses promote internalisation of Staphylococcus aureus into nonfully permissive cultured pneumocytes. Microbes Infect. 2006;8(3):758-766. doi:10.1016/j.micinf.2005.09.013

37. Nansen A, Randrup Thomsen A. Viral infection causes rapid sensitization to lipopolysaccharide: central role of IFN-alpha beta. J Immunol. 2001;166(2):982-988. doi:10.4049/jimmunol.166.2.982

38. Ripa M, Galli L, Poli A, et al. Secondary infections in patients hospitalized with COVID-19: incidence and predictive factors. Clin Microbiol Infect. 2021;27(3):451-457. doi:10.1016/j.cmi.2020.10.021

39. Zhu N, Zhang D, Wang W, et al. A Novel Coronavirus from Patients with Pneumonia in China, 2019. N Engl J Med. 2020;382(8):727-733. doi:10.1056/NEJMoa2001017

40. Kim D, Quinn J, Pinsky B, Shah NH, Brown I. Rates of Coinfection Between SARS-CoV-2 and Other Respiratory Pathogens. JAMA. 2020;323(20):2085-2086. doi:10.1001/jama.2020.6266

41. Chen N, Zhou M, Dong X, et al. Epidemiological and clinical characteristics of 99 cases of 2019 novel coronavirus pneumonia in Wuhan, China: a descriptive study. Lancet. 2020;395(10223):507-513. doi:10.1016/SO140-6736(20)30211-7

42. Rawson TM, Moore LSP, Zhu N, et al. Bacterial and Fungal Coinfection in Individuals With Coronavirus: A Rapid Review To Support COVID-19 Antimicrobial Prescribing. Clin Infect Dis. 2020;71(9):2459-2468. doi:10.1093/cid/ciaa530

43. Meier MA, Branche A, Neeser OL, et al. Procalcitonin-guided Antibiotic Treatment in Patients With Positive Blood Cultures: A Patient-level Meta-analysis of Randomized Trials. Clin Infect Dis. 2019;69(3):388-396. doi:10.1093/cid/ciy917

44. de Jong E, van Oers JA, Beishuizen A, et al. Efficacy and safety of procalcitonin guidance in reducing the duration of antibiotic treatment in critically ill patients: a randomised, controlled, open-label trial. Lancet Infect Dis. 2016;16(7):819-827. doi:10.1016/S1473-3099(16)00053-0

45. Osthoff M, Siegemund M, Balestra G, Abdul-Aziz MH, Roberts JA. Prolonged administration of $\beta$-lactam antibiotics - a comprehensive review and critical appraisal. Swiss Med Wkly. 2016;146:w14368. doi:10.4414/smw.2016.14368 